\title{
KNOWLEDGE BASED DECISION MAKING IN MECHANICAL WORKSHOPS
}

\author{
Kaarel Kruuser, Jueri Riives \& Indrek Kiolein
}
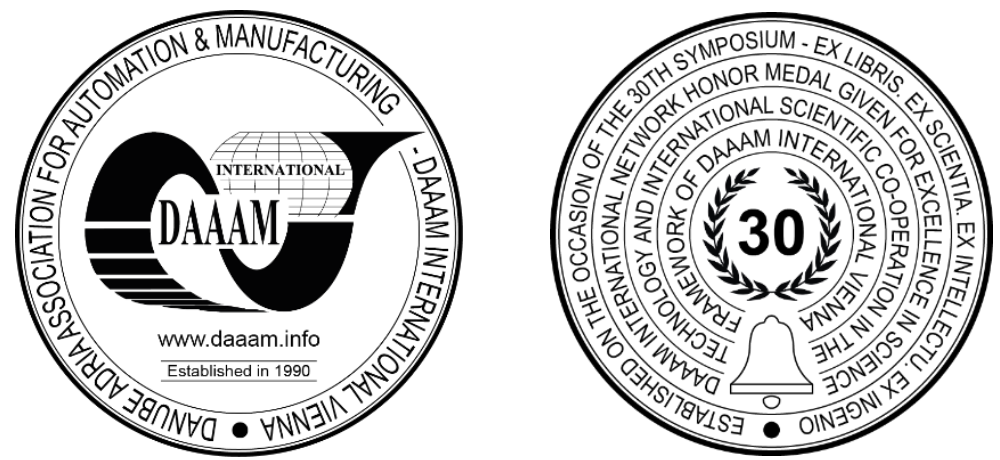

This Publication has to be referred as: Kruuser, K[aarel]; Riives, J[ueri] \& Kiolein, I[ndrek] (2021). Knowledge Based Decision Making in Mechanical Workshops, Proceedings of the 32nd DAAAM International Symposium, pp.0514-0521, B. Katalinic (Ed.), Published by DAAAM International, ISBN 978-3-902734-33-4, ISSN 1726-9679, Vienna, Austria DOI: $10.2507 / 32$ nd.daaam.proceedings.074

\begin{abstract}
Now-days manufacturing is going more complex, dynamic and changing over time even chaotic in the extended value chain. In order to being able to satisfy the demand for high-quality products in an efficient manner, it is essential to use modern technologies based on AI. These areas, which have great developments are expert systems and machine learning. These have the new challenges to manage the manufacturing in different application areas. There are different possibilities and different approaches for solving multi criteria based engineering tasks, influencing directly to the performance in a workplace. How to combine and use them to improve and manage the performance of the production process in the workplace is a main objective of the current article. The integration of the AI models with FBM templates and libraries can also give a great advantage to standardize the way of decision making in a certain product family (like injection moulds). In the article, the models from both categories considered with tooling questions have been examined. This can help improve manufacturing consistency and reduce the tool inventory by setting shop tool standards for similar operations.
\end{abstract}

Keywords: Artificial intelligence; Feature Based Machining; Machine learning; Knowledge based manufacturing.

\section{Introduction}

Production automation and digitalization is a definite trend in business today. At the same time, production technologies and the equipment that supports them are becoming increasingly complex. The goal is to produce various products in small batches, with high productivity, high quality and as efficiently as possible. For this objective the complex, dynamic and changing over time solutions are needed. In order to being able to satisfy the demand for highquality products in an efficient manner, it is essential to use modern technologies based on Artificial intelligence (AI). AI is the key driver in this change and it is critical for effective decision-making [1], [2]. These areas, which have great developments in manufacturing are expert systems and machine learning. These two components have the new challenges to manage the manufacturing in different application phases (process planning, operation planning, NC code developing, etc). 
In a small or medium-sized company that does not have its own brand or is not focused on series production, has a great challenge to prepare for production for every different detail. In addition to the company, they often specialize in a market segment, which simplifies production preparation because the products have similar technologies and can be broadly divided into families. Tool manufacturers are just the type of companies where each product is different but the manufacturing technology is similar. Knowledge is be understood as the ultimate competitive advantage, the creation and capture of value in the unpredictable fast changing conditions [3]. The products can be divided into families according to the types of manufacturing technology. Machine learning can be applied in these types of situations. By analyzing products, you can compile type technologies on the basis of which you can develop rules for the production of product manufacturing technology.

The aim of this paper is describe the ontology of discrete manufacturing and look at the possibilities of AI applications in process planning decision making. A framework for intelligent manufacturing is proposed. Based on the proposed framework, the use case is solved.

\section{Ontology in a discrete manufacturing}

Discrete part of manufacturing integrates a design, planning and execution phase in which product information is defined to a manufacturing phase in which the processes would be fulfilled in the best possible way (cost efficient, resource utilization efficient, time efficient, etc). In the process planning typically culminates with the generation of numerical control (NC) programs for specific equipment. To perform the machining process in a workshop there is needed the following decision-making tasks such as technology selection, planning of processing trajectories, optimal selection of machining tools, optimization of operational technology, quality control solutions, use of technological possibilities of machine tool, use of machine tool resources. These tasks are going more complicated as the equipment possibilities are growing constantly. Expert systems, based on accumulated and/or gathered knowledge is a justified solution.

From the other hand in manufacturing process there are different problems influencing directly to the efficiency and depending from the big number of different parameters. These are like tool life optimization, energy saving, machine tool capability utilization, etc. Having sophisticated machining centers and producing high-quality complex workpieces, these have a high significance. Production process planning (PPP) is highly knowledge-intensive activities sequence planning, considering resources, production routes (with alternatives), machining operation planning with tool path planning, fixtures and tools choosing. The production process constantly involves a large amount of data, information and knowledge, which is either static or dynamically changing during the process. As there are different users, an important contribution to the success of application, is its common taxonomy. An approach to defining manufacturing taxonomy and axioms, based on manufacturing systems engineering (MSE) ontology was presented in [4].

Ontology is a type of semantic tool providing a source of shared and precisely defined terms that can be used to describe both knowledge and concepts (see Figure 1). Ontology can be expressed in standard formal languages like XML which would ensure the shareability and cooperation. These characteristics make ontology a notable knowledge modelling tool in many domains like medical science, digital library, manufacturing [5], etc. An ontology is the representation of knowledge based on conceptualization in a formal and explicit manner [6], in another word, explicit, formal specifications of terms in the domain and of the relations among them. The advantage of ontology is that it offers the concepts and their relations in a domain in a commonly agreed and formal expression that is machine-readable [7] and it has the reasoning capability that makes the implicit information explicit [8].

The described ontology model (see Fig.1) is the bases for development of models for the manufacturing process and the creation interaction of data, information and knowledge (see Fig.4., Fig. 9.) The ontology reflects the relationships and dependencies of the business model and the production process; production process and product; product and technology; technology and device, etc. By filling these attributes with data and analyzing the values of the output parameters, process performance can be optimized. The landscape where easy-to-understand and rational decisions and solutions for complex systems and relationships are sought is illustrated in Fig. 2.

The input is a manufacturing task: $\{$ product type $=$ plate; parametrical model $=$ CAD model $\}$.

Decisions in the operation level:

- optimal sequence of machining;

- optimal selection of tools;

- optimal cutting conditions;

- tool life optimization. 


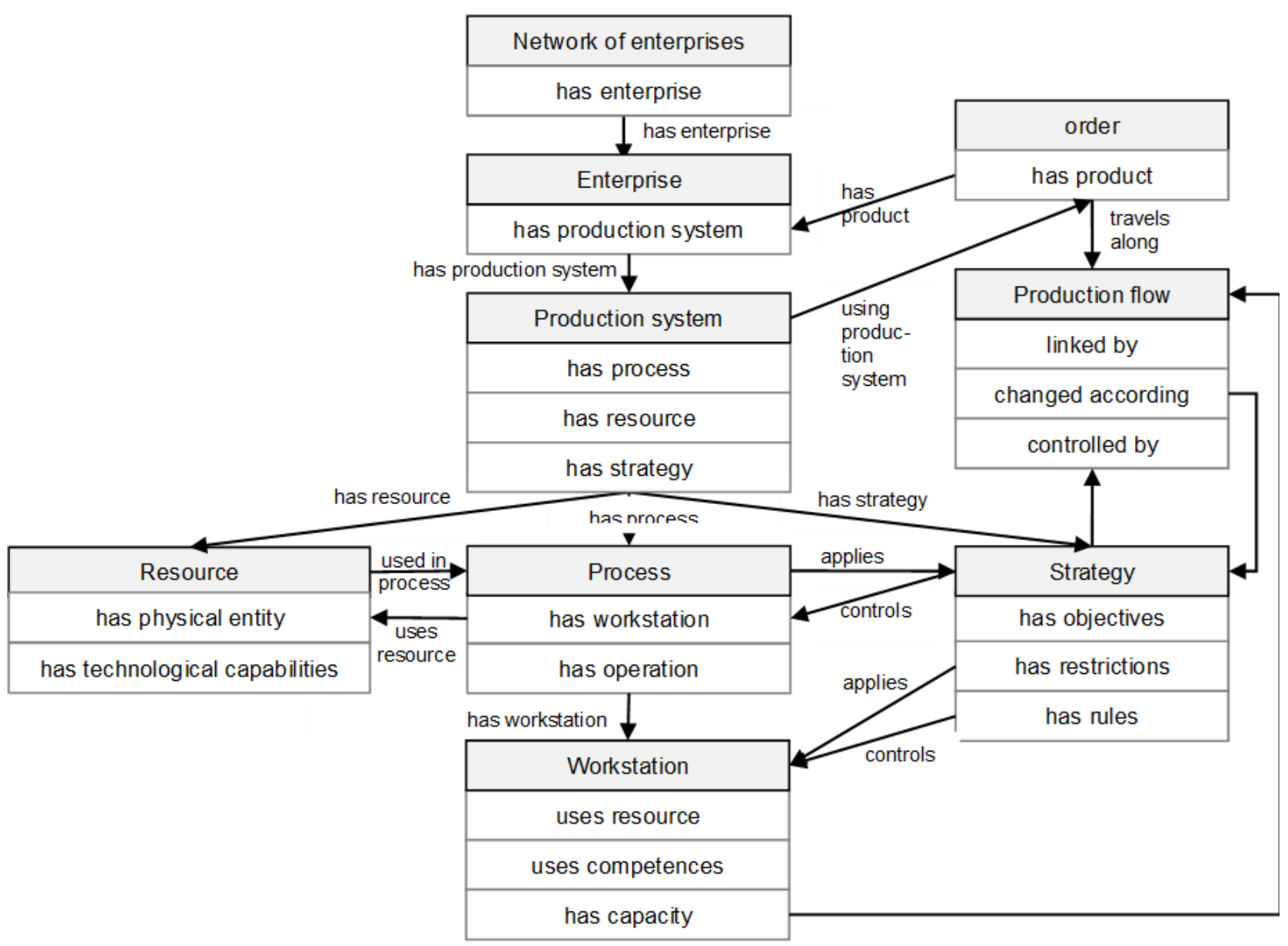

Fig. 1. Ontology of modern manufacturing

Decisions on the production system level:

- optimized total throughput time;

- optimized OEE;

- optimized SMED.
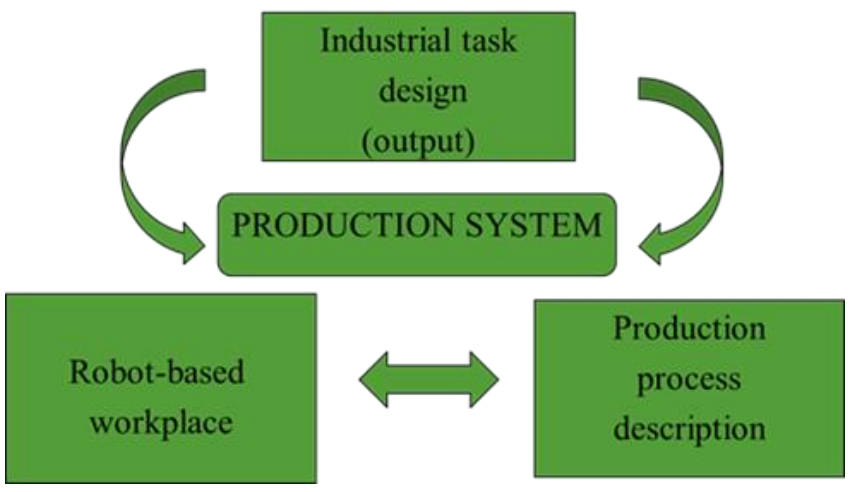

Fig. 2. Basic relationships in manufacturing

For the decisions of abovementioned parameters there are three data and knowledge flows:

- theory (theoretical models);

- recommendations from suppliers of equipment, instruments, etc.;

- knowledge, accumulated by practice.

These all are as input for the knowledge - based decision-making. 


\section{AI application possibilities in process planning decision making}

There has been developed a feature-based machining approach for the sophisticated parts and 5-axes machining centers. The principles of using feature - based machining (FBM) methods were described in [7]. Today's production is characterized by: a reduction in batch sizes, a shorter time to market, increased quality requirements and increased price pressure. The equipment and technologies used, are increasingly complex and have a wide range of technological capabilities. All this creates certain complications for SMEs. There is no exception also the tooling industry.

A two-level approach is needed to make production more efficient. First, it is important to quickly identify the product and its features. There is need to classify and to systematize these, and to develop the processing technologies for different features shape clusters. On the other hand, workplace performance is shaped by productivity, the sustainable use of resources and the cost of meeting quality requirements. Mathematical models and decision-making plays an important role here. An example of a productivity model is given below (1), which takes into account the nature of the product and its features, the technological possibilities of the machine tool and the process planning principles.

$$
Q=\frac{n s}{(n s) * \frac{l_{x x}}{s_{x x}}+(n s) * I A * t_{y}+(n s) * t_{s}+\frac{(n s) * l_{x z}}{s_{x z}}}
$$

Where, $\mathrm{n}$ - spindle speed ( $\mathrm{sec})-1, \mathrm{~s}$ - tool feed $(\mathrm{mm} / \mathrm{sec}), 1 \mathrm{xx}-$ the length of the path that the tool travels with a quick placement from one feature to another $(\mathrm{mm})$, sxx -Machine Rapid movement time (sec), IA - number of tools used, tv tool exchange time (sec), ts - setup time ( $\mathrm{sec}$ ), lxz - tool rapid movement length in tools axis (mm), sxz - machine rapid movement speed in $\mathrm{Z}$ axis. The problem is the constant change of product nomenclature, the constant improvement of the company's strategies, as well as technological equipment and accompanying technologies. Static models do not work here and flexibility has a great importance. Here has been developed a framework for intelligent manufacturing. This framework consists of four basic frames having different objectives (see Fig. 3.). The framework is based on the ontology model (see Fig. 1). These frames are all as independent parts that have tight interactions. Content of the frames depends on the manufacturing application. Example of the realization of the framework for real manufacturing task solving is given on the bases of a use-case:

1. Parametric frame for part unification with corresponding grouping the features and realizing the possibilities for feature - based machining.

2. Process frame, using AI based rules and patterns is used for optimal decision making in process planning activities. The process frame is working in interaction with the parametric frame.

3. Data frame lays on the physical content of the manufacturing system and the data output depends from the technological capabilities of equipment used, but also how these are used in the production process. Therefore, the data models here are the important part and logic for data obtaining and analysis.

4. Analysis frame is working tightly together with the data frame and machine learning algorithms are used for process improvement.

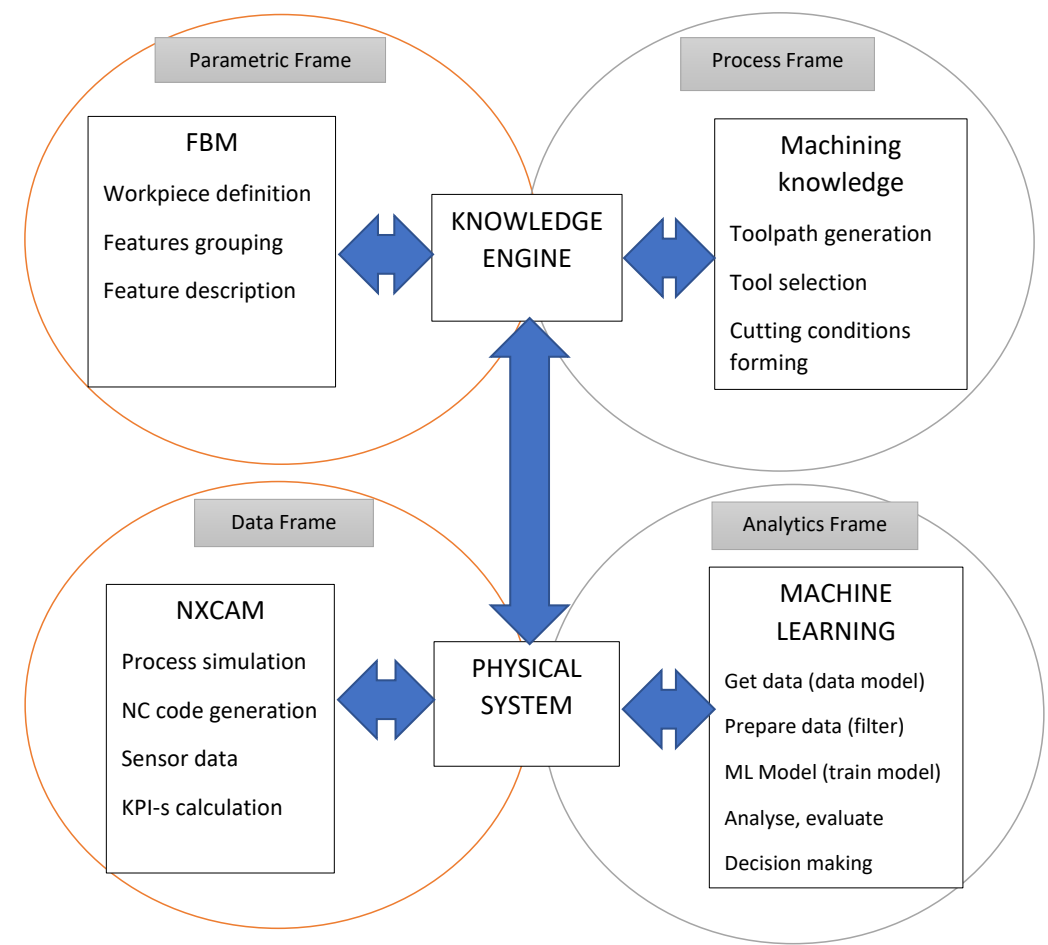

Fig. 3. Framework of intelligent manufacturing 
Feature based machining is based on the principles that using designed rules, we can compile the machining of a certain workpiece (using catalogues of standard technologies and feature classification principles) according to a predicted logic. In principle, the CAD model of a product must be transformed into a language understood by the machine control software (such as NX CAM) of the machining center and the device must be "trained" to manufacture this product intelligently. Here we come across the principles of machine learning.

Machine learning is a possible tool in these situations. Machine Learning is a branch of computer science that enables computers to act without explicitly programmed. Machine learning uses statistical and pattern matching techniques to accomplish prediction and data analysis task. Moreover, machine learning is a subfield of artificial intelligence. Its goal is to enable computers to learn on their own. A machine's learning algorithm enables it to identify patterns in observed data, build models that explain the world, and predict things without having explicit pre-programmed rules and models [8].

In machine learning, the major objective is to find a model or function that maps input variables to output variables. Consider we have set of input variables $(\mathrm{X})$ and set of output variables $(\mathrm{Y})$, the objective of machine learning is to find a function $\mathrm{f}$ that maps the input variable $(\mathrm{X})$ to $(\mathrm{Y})$. There are different possibilities and different approaches for solving multicriteria based engineering tasks, influencing directly to the performance in a workplace. How to combine and use them to improve and manage the performance of the production process in the workplace is a main objective of the current article. The integration of the AI models with FBM templates and libraries can also give a great advantage to standardize the way of decision making in a certain product family (like injection moulds). In the article the models from both categories considered with tooling questions have been considered. This can help improve manufacturing consistency and reduce the tool inventory by setting shop tool standards for similar operations

Machine learning describes a set of techniques that are commonly used to solve a variety of real-world problems with the help of computer systems which can learn to solve a problem instead of being explicitly programmed. [9]. Here the role of big data in decision making was examined [10], [11]. Within the context (see Fig.1, Fig3 and productivity model) the production process is represented by big data attributes, considering workpiece, feature, machine tool, cutting tool, machining process, cutting conditions and machining results (cycle time, operation fulfilment time, production cost). Data classification, decision trees, decision making rules are developed using big data patterns and artificial neural networks for determining the reasonable solutions in an on-line and off-line manufacturing process. Some examples are described in the following use-cases. In the analysis phase is the interaction of input parameters \{cutting conditions, tool selection, tool life \} with the output parameters \{productivity, machine utilization rate, main drive power utilization rate\}. The objective is to minimize the cycle time (increase the productivity) with low manufacturing cost.

Additionally, there are a lot of process parameters, which have an influence to the cycle time and productivity. Here we have considered: number of tools used for machining and their allocation in tool magazine [12], tool path optimization and operation sequencing [13], sequence of machining one feature, sequence of machining the features, optimization of cutting parameters, etc. For developing basic rules there is necessary the classification of workpieces and to use the possibilities of group technology. Some examples, based on the above-mentioned logic, are described in the following use-cases.

\section{Practical use cases of FBM with the AI application}

\subsection{Production flow and engineering tasks in mechanical workshops.}

There are always certain basic rules, based on the production process. In order to start a production process, there must be production resources that allow the process to take place. Work centers, cutting instruments and fixtures can be considered as production resources. With these resources, we can add value to the raw materials. The more complex the processing process, the greater the added value it brings to the product.

In addition to production resources, production must have production processes. Describing the production process as accurately as possible and without excessive noise allows for efficient production. The more precisely and clearly understood the production process is described, the more efficiently it can be realized. In order to describe the production process more efficiently, production processes must be standardized. In an ideal world, the whole process could be standardized according to the same principles. Unfortunately, this cannot be done in real production, because the products are different and the same technological solution cannot be used. However, it is possible to divide the products into groups or families on the basis of similarities, on the basis of which similar basic principles can be used in the development of standard technologies. This allows you to optimize the production process and reduce the cost of processing the production resource.

There is no one-size-fits-all solution for optimizing manufacturing technology. The solutions are different and give different results. The choice of technology largely depends on the processing equipment and the choice of instruments used by the company. However, there are still many specific flaws in the implementation options. However, not all options are as effective and equal, although they may eventually lead to the same result. There is an alternative technology to each technology, but it may not be as effective.

As the Fig. 4. shows, how the data moves and how many different results can be obtained to produce a single feature element. When creating a work path, different inputs must be considered in order to achieve the most efficient work path. Even a small change in one parameter can drastically change the result achieved with the path. 

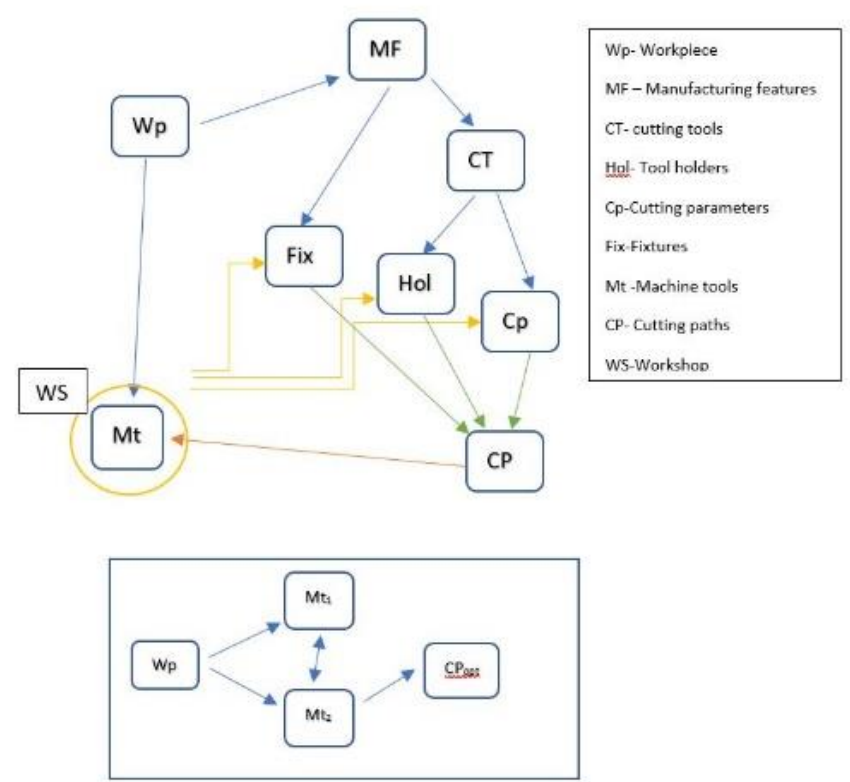

Fig. 4. Data movement in Cutting path decision making

Traditionally process parameters are determined by the operator's experience, the conservative technological data provided by the machining equipment manufacturers and trial-and-error operations. This leads to inconsistent machining performance since operator's experience is limited and subjective while the manufacturer data is based on safetyconscious principles and it only includes applications on certain machining materials.[14] Optimizing the process parameter makes it possible to record the company's knowledge and knowhow. When an employee leaves the company then such action does not leave a big knowledge gap to the company's manufacturing knowhow.

\subsection{Use case}

Let's take a closer look at the use case. In the production of injection molds, there is a situation where a single part produced is never identical to the previous one, but this production technology is always similar. Based on this, we can divide the products into families. Let's look at plate-type products and how to produce them, and how you integrate machine learning technology into production preparation. For plate type products, illustrated Fig. 5. We see different types of geometries that have different workmanship and quality requirements. The information required for production is attached to the 3D model with PMI information

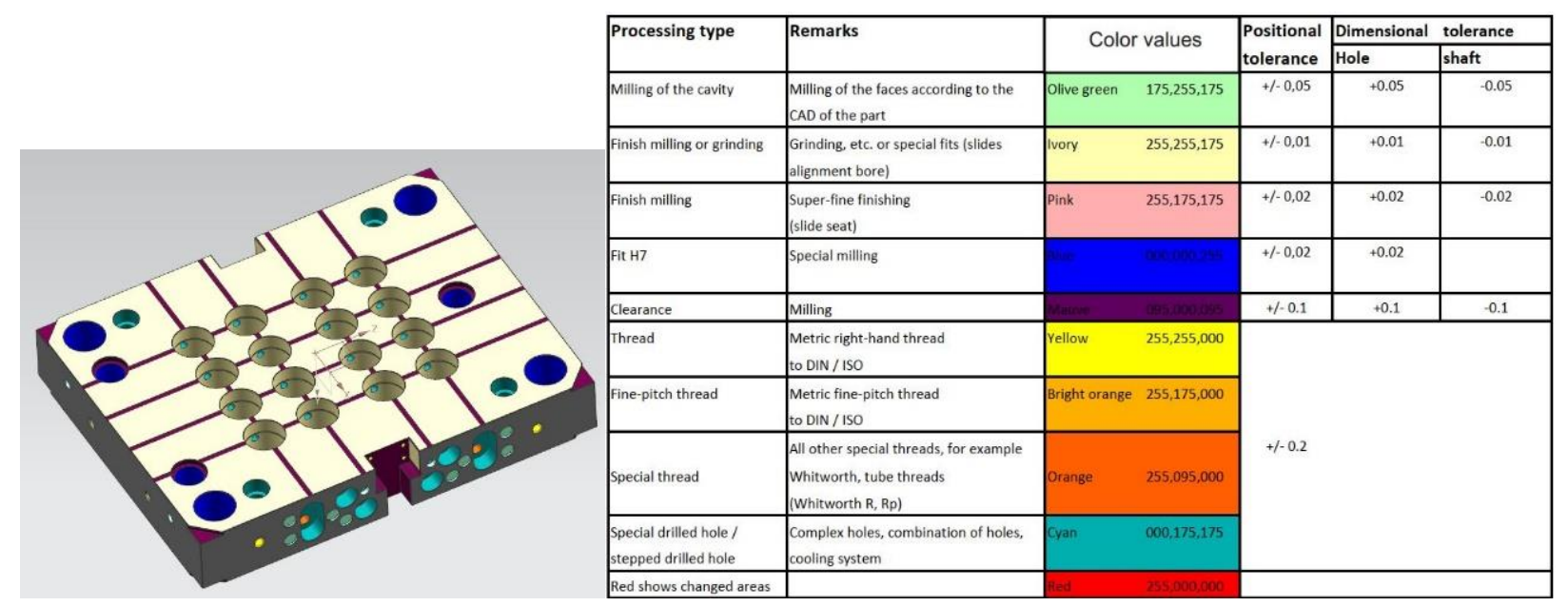

Fig. 5. Plate type product with production information applied with PMI information

We focus on one specific feature and analyze the technology needed to make it so that the image meets the set quality requirements. For analysis, we select the insert cavity, shown in Fig 6., And consider what the output variables must be. What results are expected from this product. 


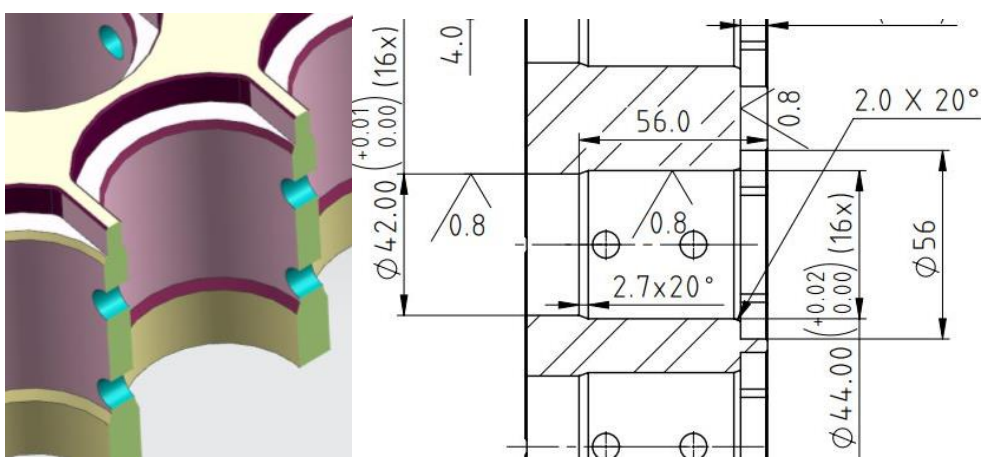

Fig. 6. Feature in plate type product, with PMI data and drawing data

Many different technologies can be used to make this feature, shown in Fig. 7. The choice of which may depend on the experience of the engineer and the work experience in the given company. Each technology has different efficiencies and easily produces different results. The development of standard manufacturing technology for this design makes it possible to keep efficiency and manufacturing costs stable, as well as to ensure stable and consistent quality.

\begin{tabular}{|l|}
\hline Rough milling $\rightarrow$ Semi finish milling $\rightarrow$ Finish milling $\rightarrow$ Chamfering \\
\hline Drilling $\rightarrow$ Semi finish milling $\rightarrow$ Finish milling $\rightarrow$ Finish Boring $\rightarrow$ Chamfering \\
\hline Rough milling $\rightarrow$ Semi finish milling $\rightarrow$ Finish milling $\rightarrow$ Finish Boring $\rightarrow$ Chamfering \\
\hline
\end{tabular}

Fig. 7. Different types of production technology for the feature.

When choosing needed technology, it is important to choose the appropriate instruments and cutting parameters for machining. There are different instruments in the factory that can be used to perform the same technology, see Fig 8. But different instruments do not have the same efficiency in performing the same technology. The instruments work with different parameters in different materials, and with incorrect parameter, the tool does not work effectively or can even break.

\begin{tabular}{|c|l|l|l|l|}
\hline $\begin{array}{c}\text { Technological } \\
\text { operation }\end{array}$ & Type & $\begin{array}{l}\text { Cutter } \\
\text { diameter }\end{array}$ & $\begin{array}{l}\text { Cutting } \\
\text { edge radius }\end{array}$ & $\begin{array}{l}\text { Nr. Of } \\
\text { flutes }\end{array}$ \\
\hline \multirow{3}{*}{ Rough milling } & Indexable & 18 & 0.8 & 3 \\
\cline { 2 - 5 } & Indexable & 18 & 1.8 & 3 \\
\cline { 2 - 5 } & Endmill & 18 & 0.5 & 3 \\
\hline
\end{tabular}

Fig 8. Selection of instruments on same technological operation.

In order to use Machine learning applications, the tools, modes and technologies used in the factory must be mapped and corresponding databases must be created. This allows data to be used in the machine learning process.

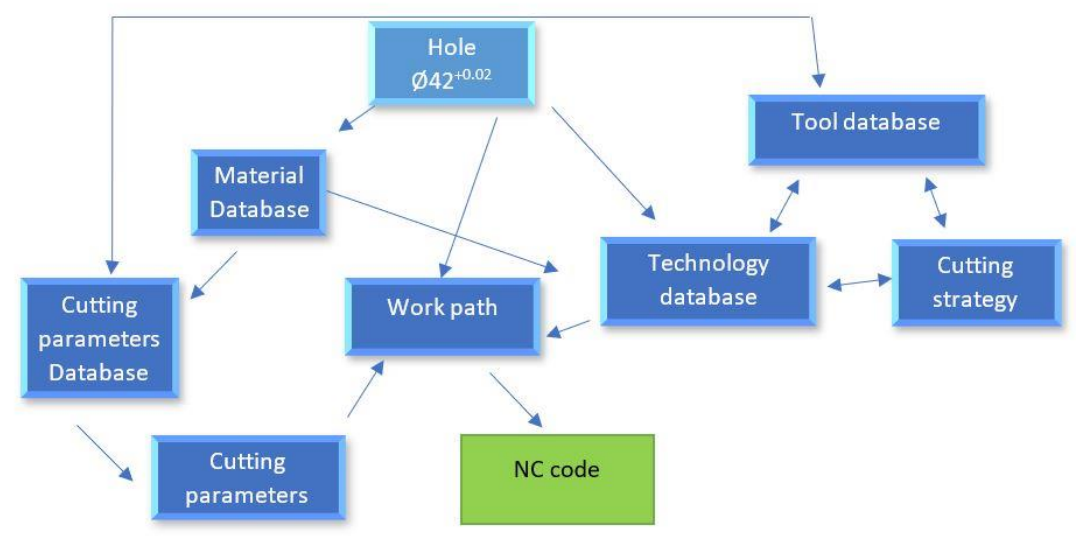

Fig. 9. Decision making in Feature machining 
As described on the Fig. 9, first input comes from the features, which describes the geometry and processing requirements (tolerances and surface quality). In order to compile the technology, a suitable cutting strategy must be selected, based on the choice of material and tool. Technology is chosen first. Depending on the technology chosen, tools and cutting strategies will be selected for each operation. To do this, the tools in the tool database are compared according to which tools are available for this type of operation. The tools are selected according to the optimal diameter and the appropriate tool geometry. When the optimal tool is found, the appropriate parameters are searched in the table of cutting parameters based on the material of the workpiece. If the tool does not fit, the next tool is selected based on the geometry fit. Depending on the choice of technology and tool, it will choose a cutting strategy. As a result, a work path is generated from which the NC code can be generated using the postprocessor.

In order to make the rules for technological selection, the capabilities of the workshop must first be examined and the rules must be adapted to the possibilities. Rules that do not support the technological capability of workshop are ineffective and rather harmful.

\section{Conclusions}

To automate and digitize increasingly complex technologies, dynamic solutions that adapt to time is needed to be developed. These solutions must meet the needs and capabilities of the company and be able to adapt to the changes taking place in the company. This article described the ontology of modern production and relationships involved in manufacturing. The role of big data in decision making was studied. Based on the proposed framework, the use case solution was presented. So far, the research has mainly focused on developing a theoretical framework for decision making. The next step of research is to monitor the operating parameters of the equipment and to collect information on the efficiency in relation to the cutting parameters used. Based on this data, develop a decision-making smart system to select more efficient parameters.

\section{References}

[1] Buchmeister, B; Palcic, I.; Ojstersek, R. (2019). Artificial Intelligence in Manufacturing Companies and Broader. An Overview. DAAAM International Scientific Book (pp 81-98). DAAAM International Publishing.

[2] Plant Automation (2019). Technology: The future of artificial intelligence in manufacturing industries, Available from: https://www.plantautomationtechnology.com/articles. Accessed on 2019-03-10

[3] Henriques, E.; Peças, P. (2012). New Business Models for the Tooling Industry. In book: Advances in Business and Management - Vol.4 (pp.1-33) Publisher: Nova Science Publishers, New York Editors: W.D. Nelson.

[4] Lõun, K.; Riives, J.; Otto, T. (2011). Evaluation of the Operation Expedience of Technological Resources in a Manufacturing Network. Estonian Journal of Engineering, 2011, 17,1, pp51-65

[5] Huang1, Z; Qiao1, L; Anwer, N; Mo, Y. (2014). Ontology Model for Assembly Process Planning Knowledge. 21st International Conference on Industrial Engineering and Engineering Management 2014 (IEEM 2014)

[6] Lu, Y. ; Panetto, H. ; Ni, Y. ; Gu, X. (2013). Ontology alignment for networked enterprise information system interoperability in supply chain environment. In. J. Comp. Integ. Manufac. 26(1-2), 140-151 (2013).

[7] Kruuser, K.; Riives, J. ; Tšukrejev, P. ; Kiolein, I. (2019). Implementation of a knowledge-based manufacturing on the example of Sumar Tools OÜ. Proceedings of the Estonian Academy of Sciences, 2019, 68, 4, 407-412

[8] Wuest, T.; Weimer, D.; Irgene,C.; Thoben, K. (2016) Machine learning in manufacturing: challenges and applications. Production and Manufacturing Research, 4. 1., 23-45, 2016

[9] Kühl, N.;Goutier, M.;Hirt, R. ;Satzger, G.; (2019). Machine Learning in Artificial Intelligence: Towards a Common Understanding, Proceedings of the 52nd Hawaii International Conference on System Science, Grand Wailea, Maui, Hawai.

[10] Fan, J.; Han, F.; Liu, H. (2014). 'Challenges of big data analysis', National Science Review, 1 (2), pp. $293-314$.

[11] Jeble,S., Kumari, S., Patil, Y. Role of Big Data in Decision Making. Operations and Supply Chain Management. V.11, N. 1. 2018, pp 36-44

[12] Dereli,T.; ,Filiz,I.H. (2000). Allocating optimaal index positions on tool magazines using genetic algorithms. Robotics and Autonomous Systems, 33 (2-3), pp 155-167

[13] Guo, Y.W.; Mileham, A.,R.; Owen, G.W.; Maropoulos, P.G.; Li,W.D. (2009). Operation sequencing optimization for five-axes prismatic parts using a particle swarm optimization approach. Proceedings of the Institution of Mechanical Engineers. Part B - Journal of Engineering Manufacture, 223 (5), pp 485-497

[14] Krishna Mohana Rao G.; Rangajanardhaa G.; Hanumantha Rao D.; Sreenivasa Rao M. (2009). 'Development of hybrid model and optimization of surface roughness in electric discharge machining using artificial neural networks and genetic algorithm', J. Mater. Process. Technol., vol. 209, no. 3, pp. 1512-1520, 2009 